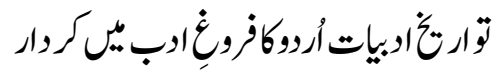

\title{
Importance of the History of Urdu Literature
}

Shazia Naseem

Federal Urdu University of Arts, Science and Technology Islamabad, Pakistan

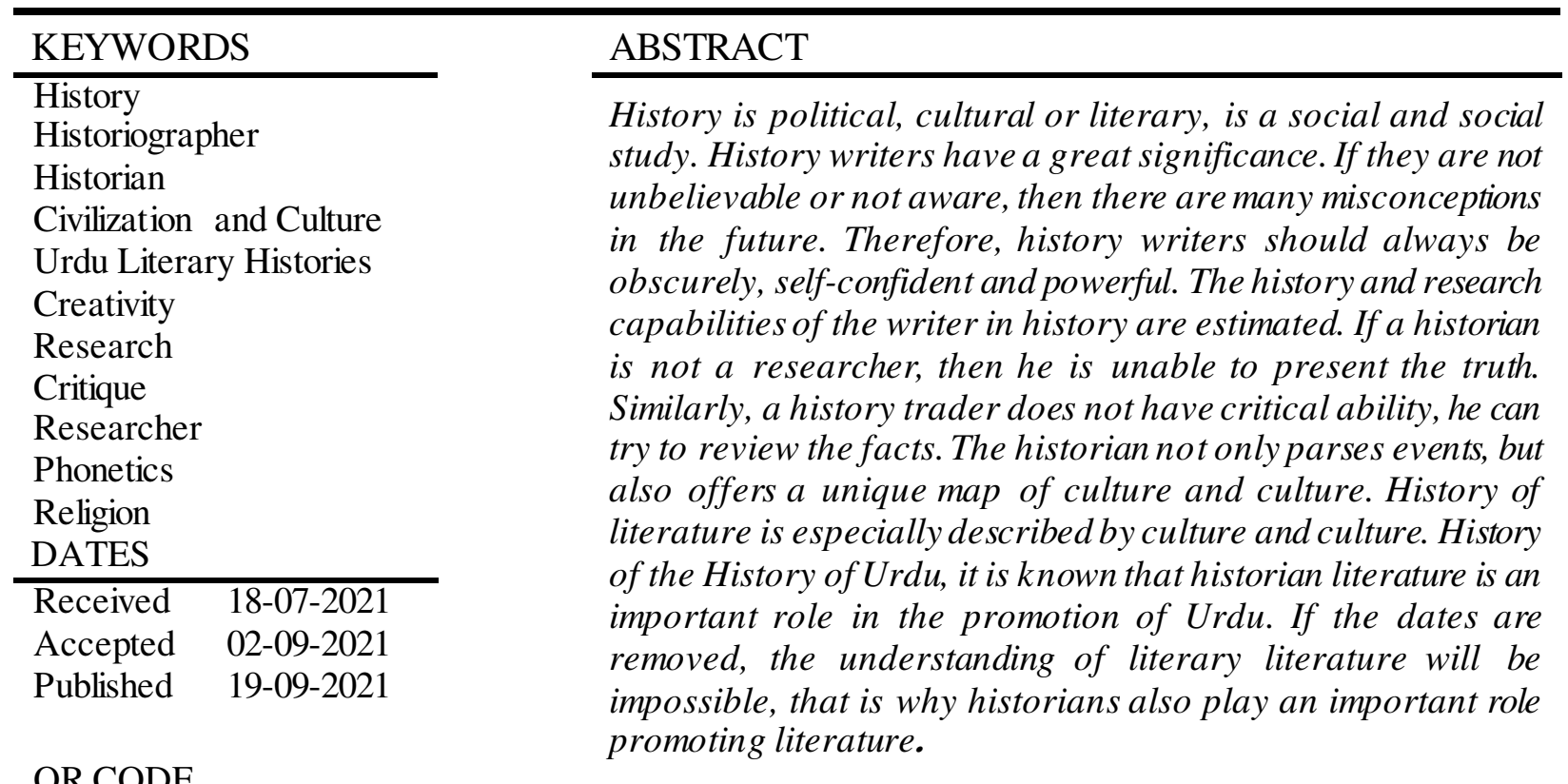

DOI: https://doi.org/10.54064/negotiations.v1i2.10

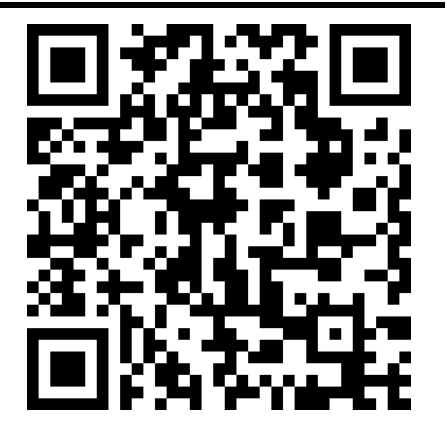

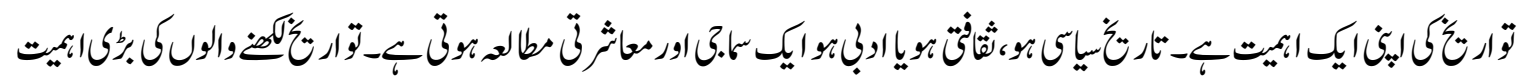

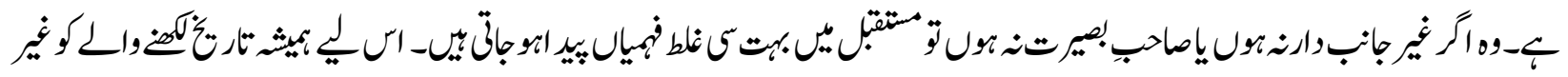

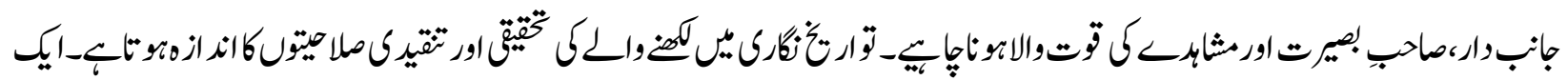

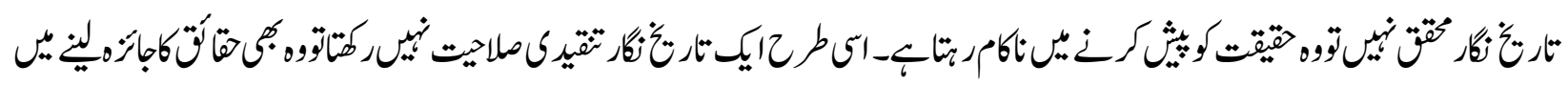

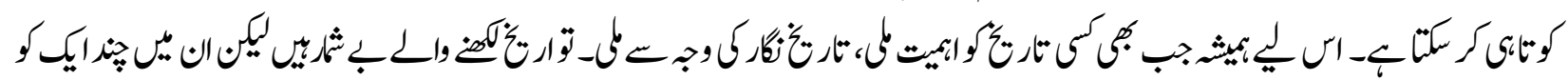

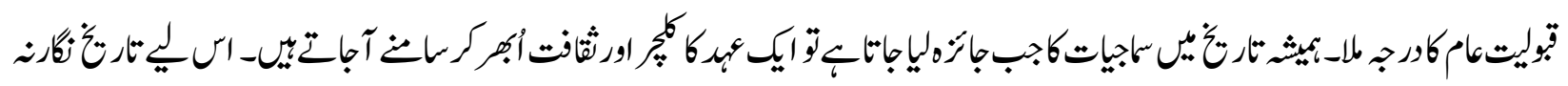

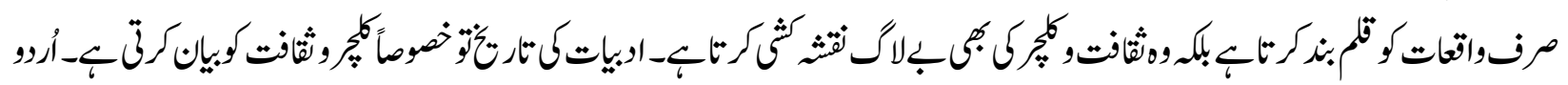




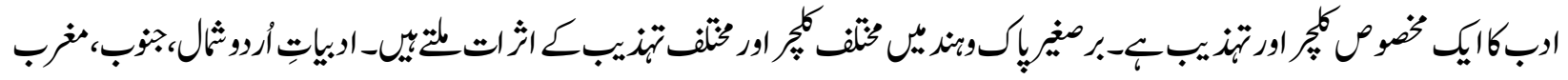

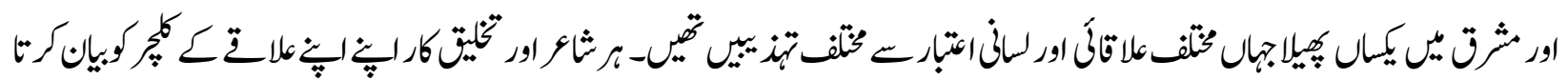

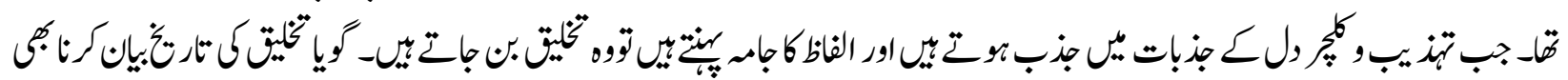

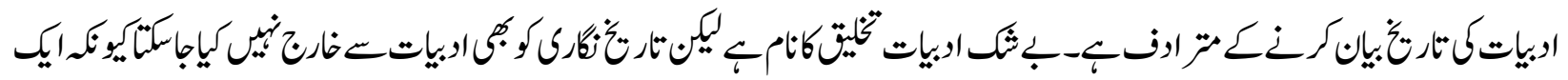

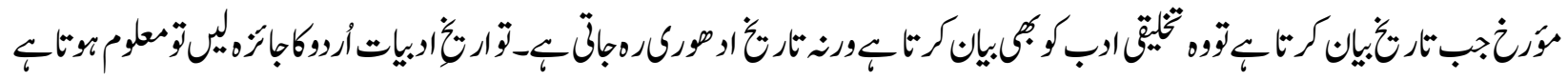

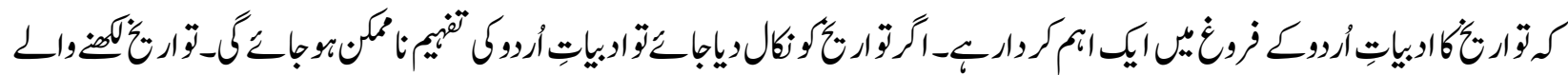

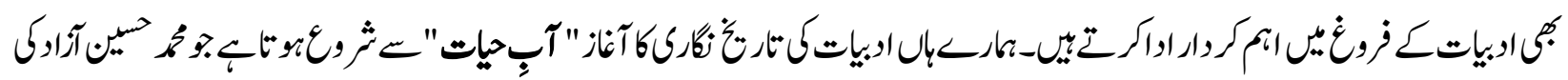

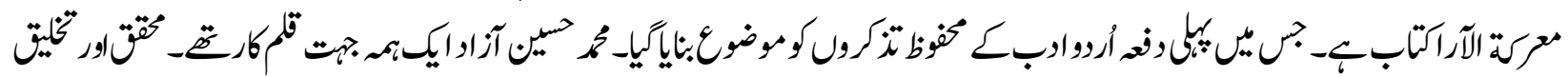

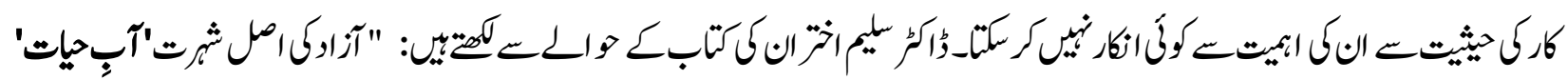
(1/AN1)

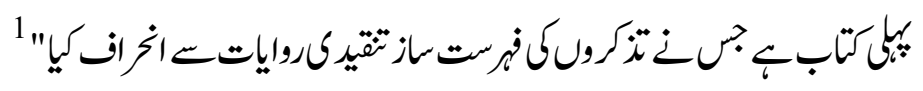

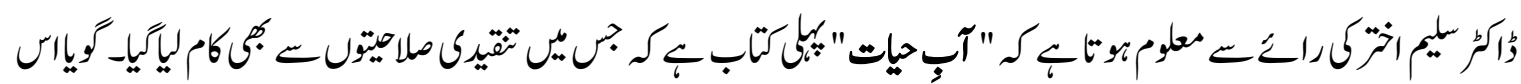

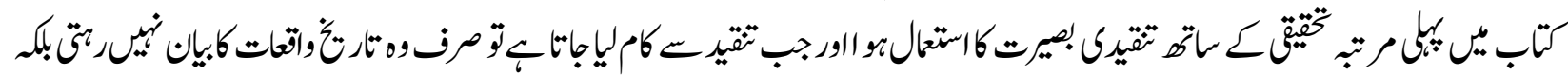

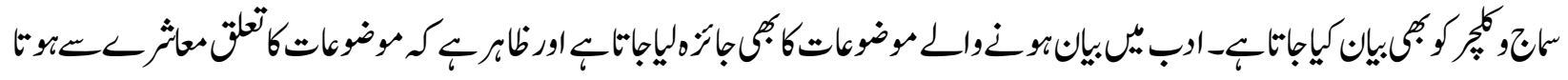

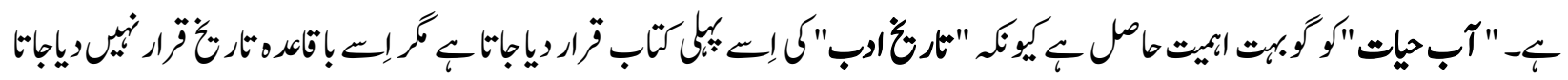

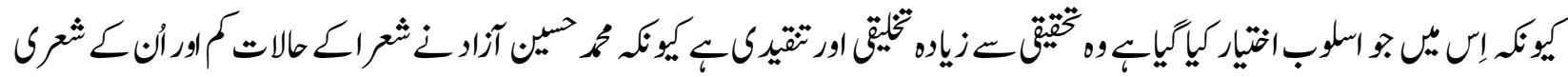

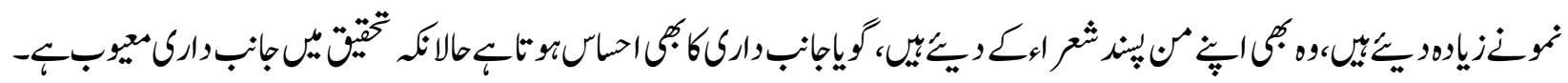

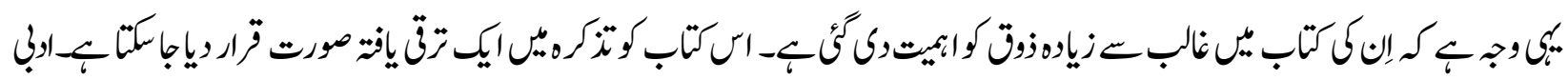

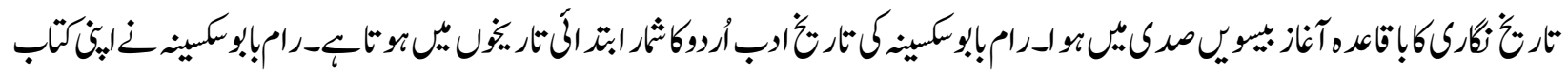

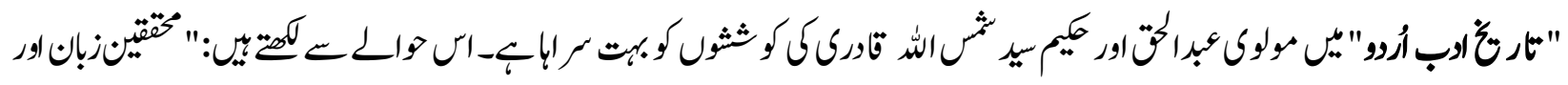

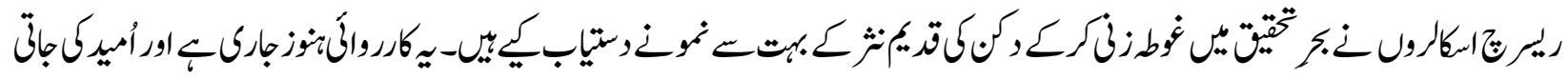

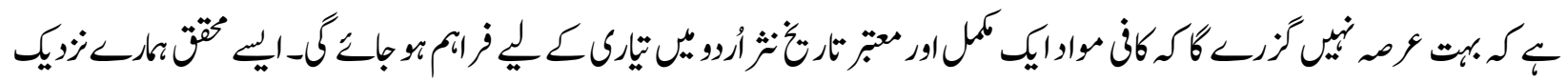

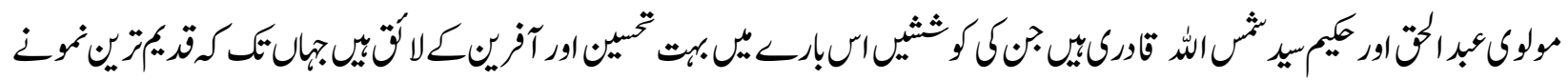

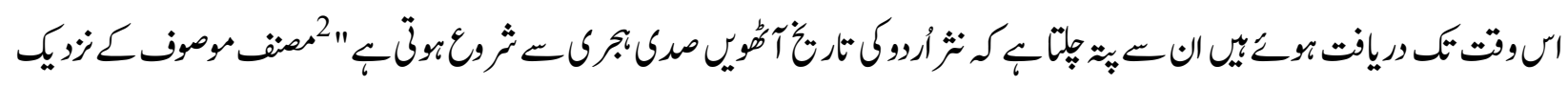

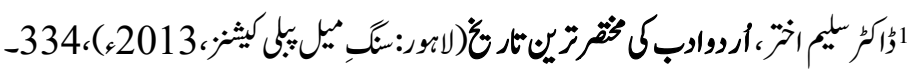

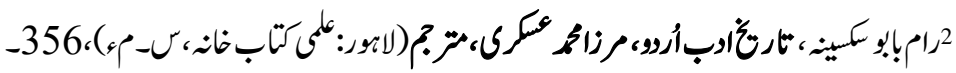




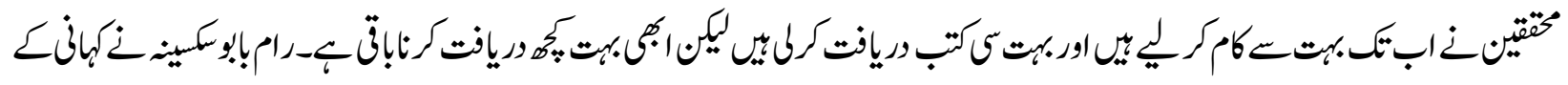

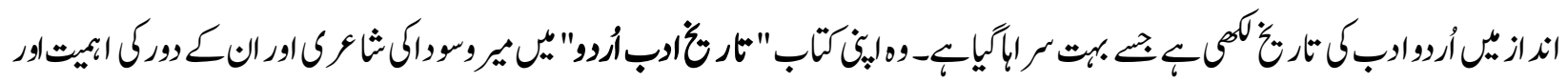

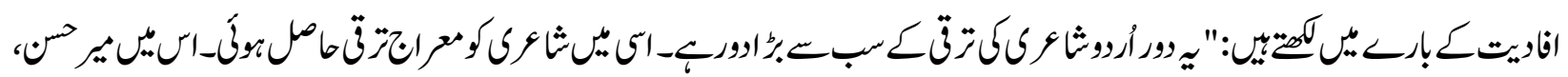

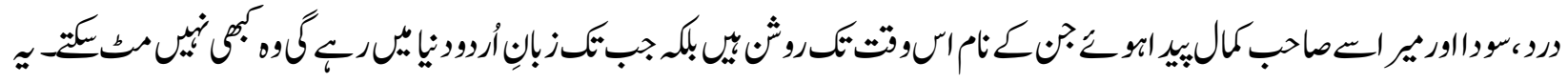

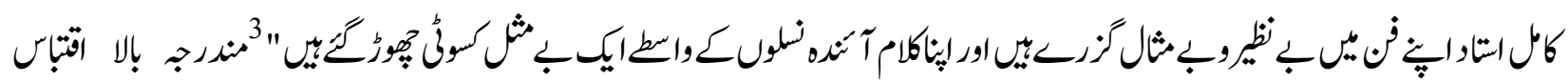

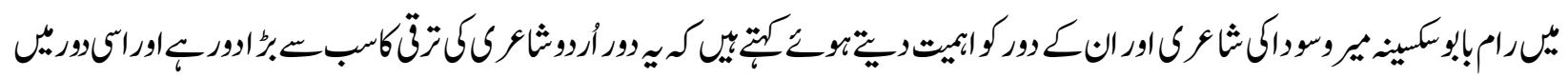

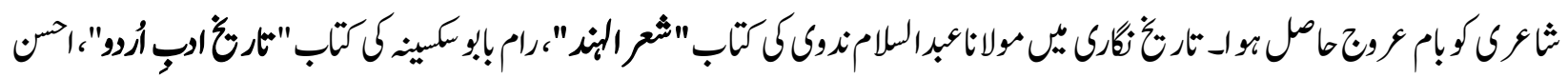

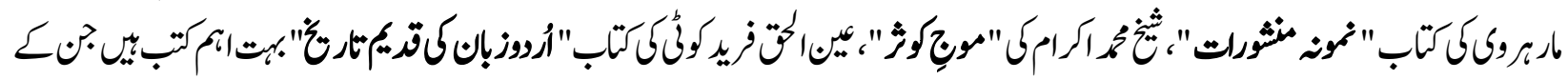

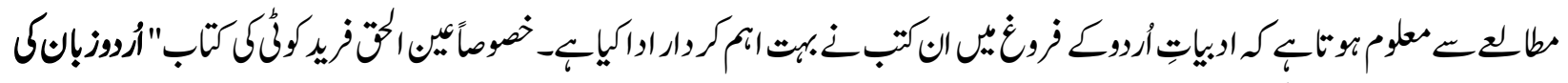

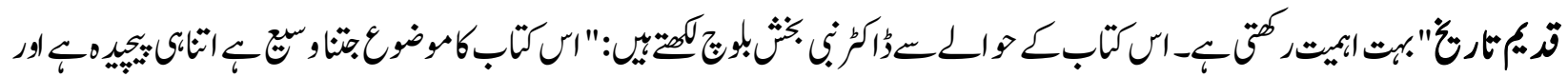

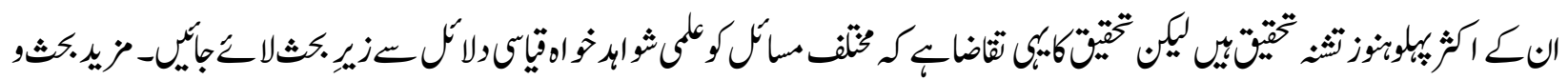

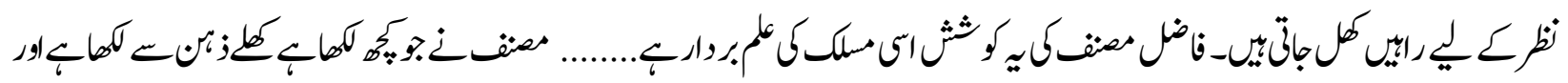

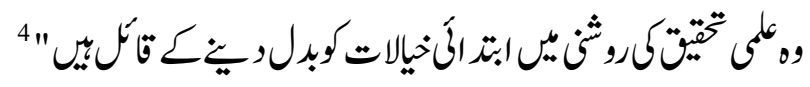

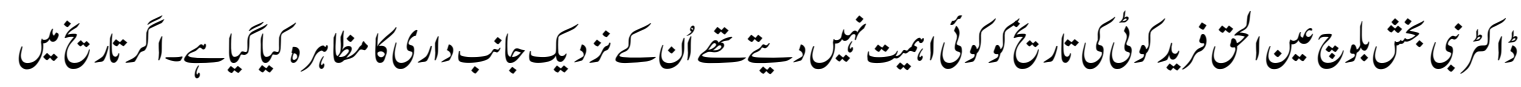

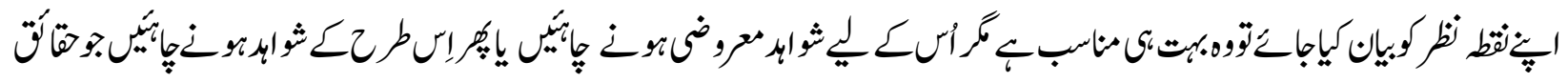

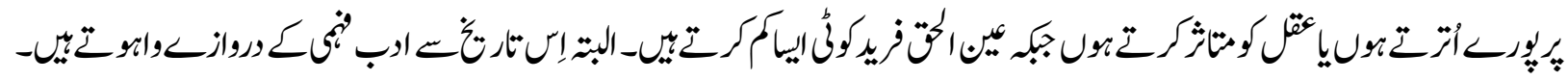

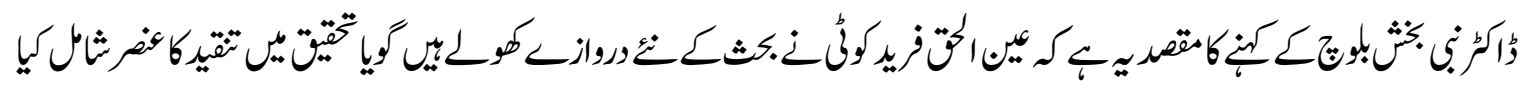

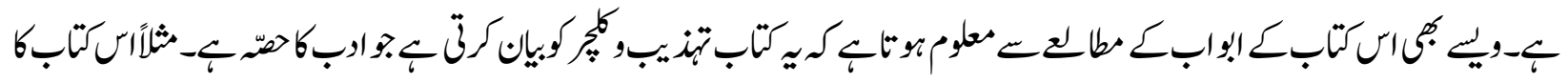

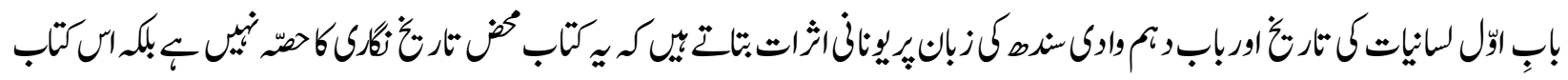

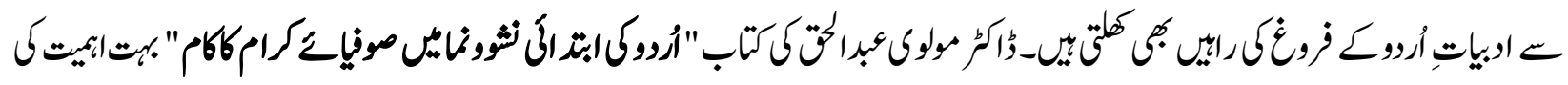

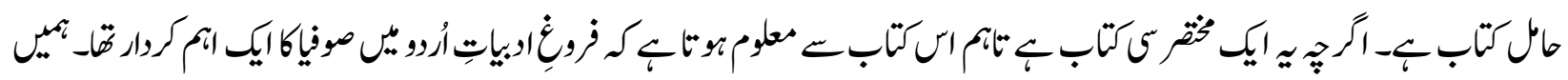

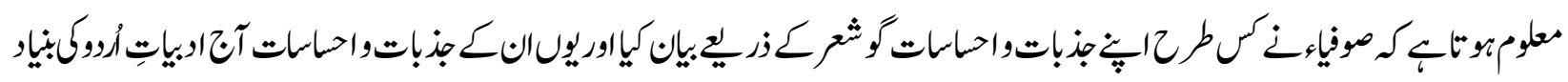

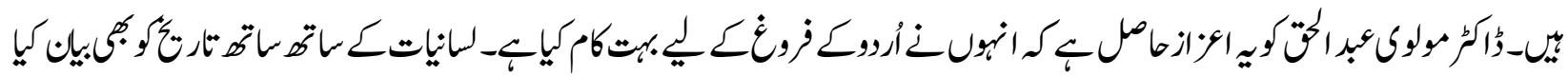

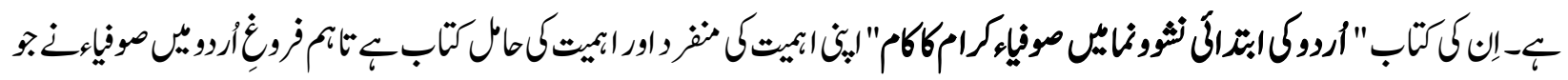

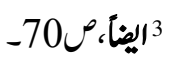

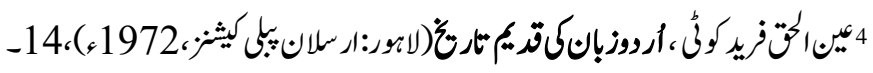




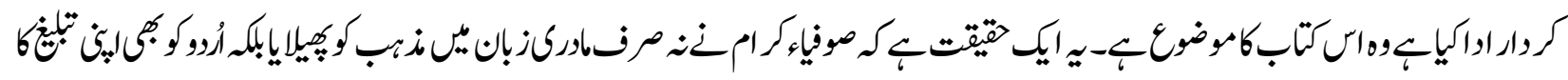

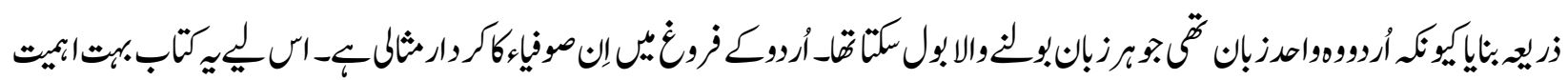

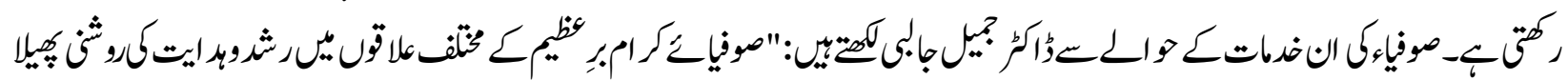

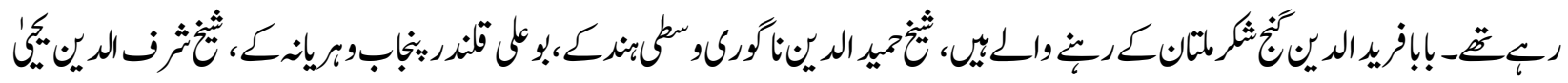

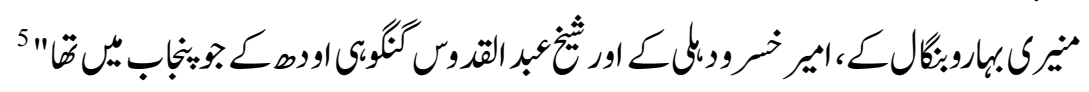

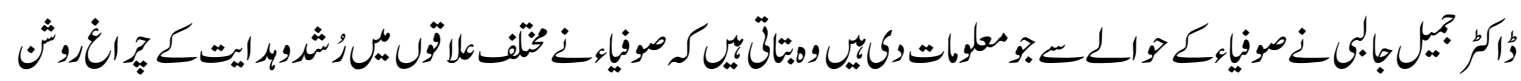

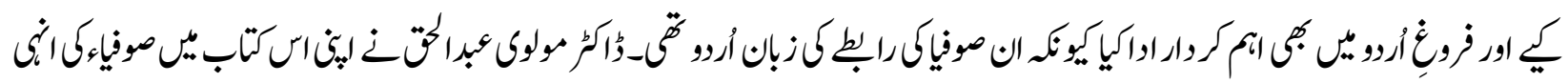

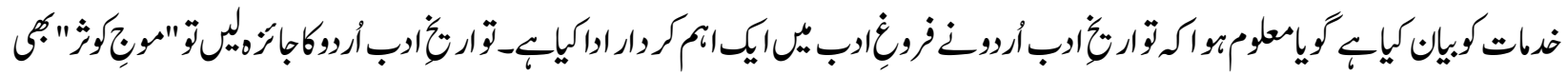

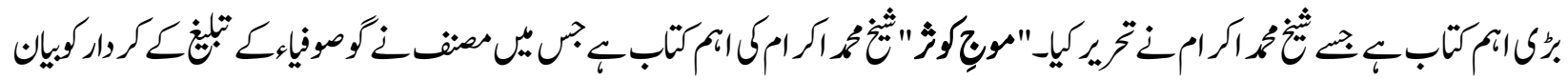

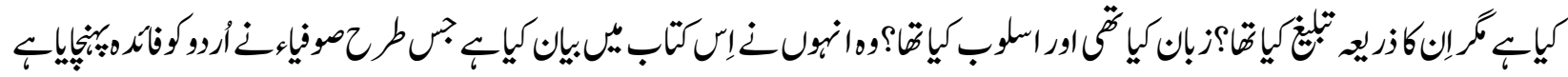

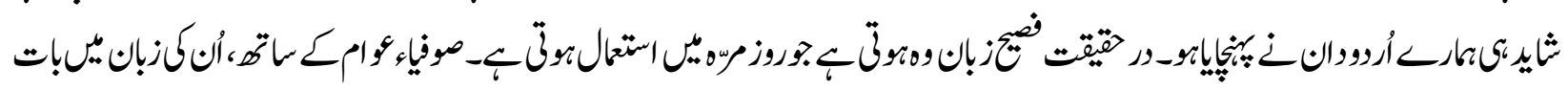

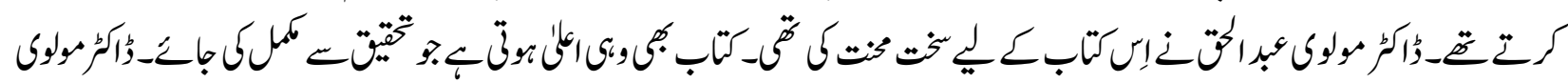

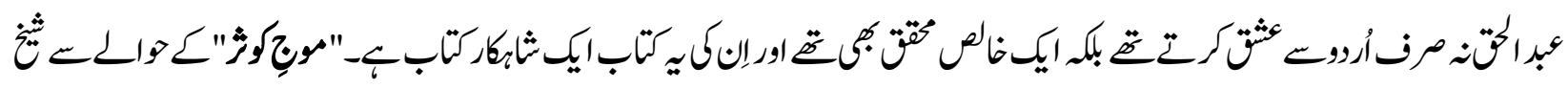

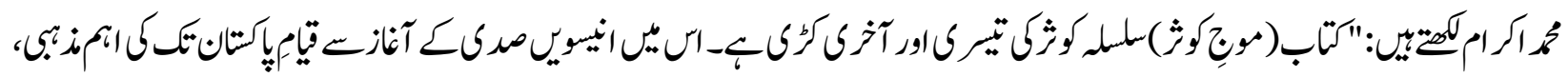

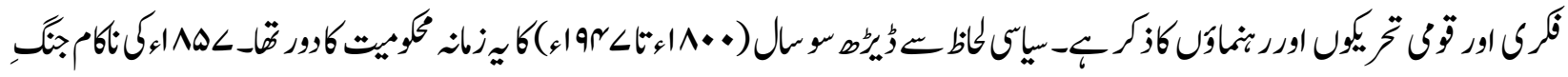

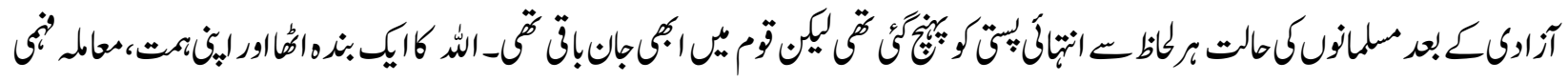

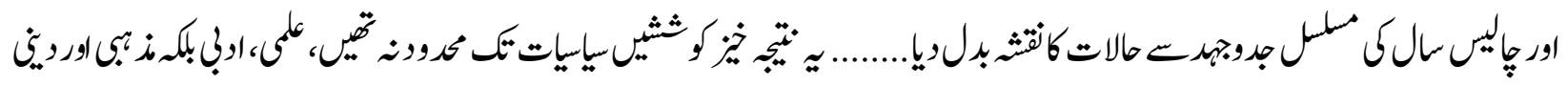

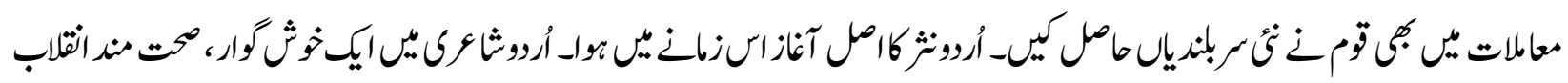

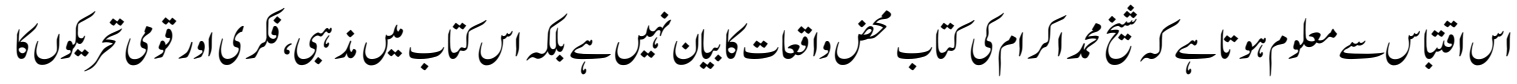

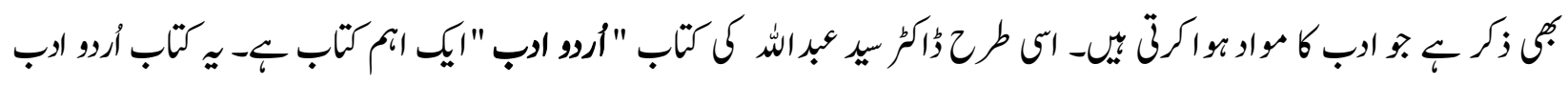

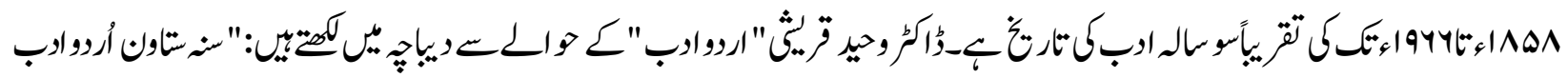

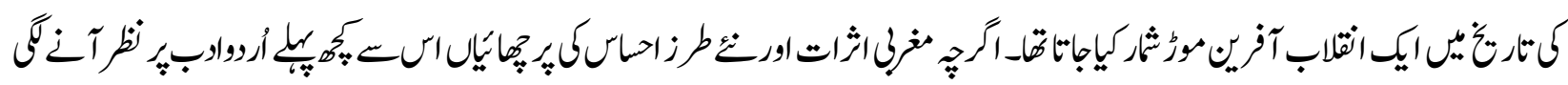

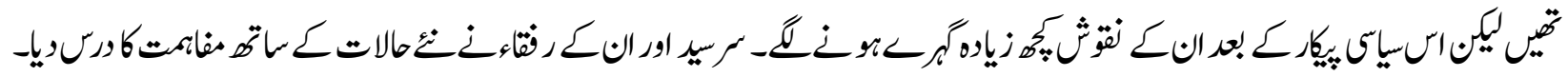

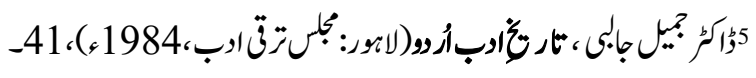

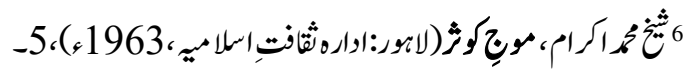




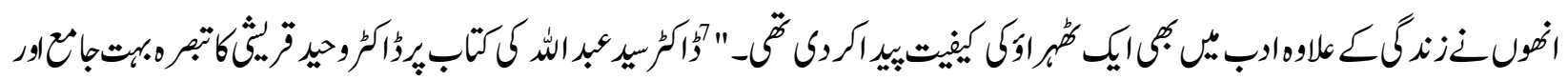

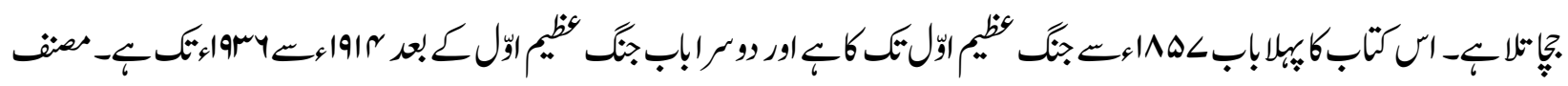

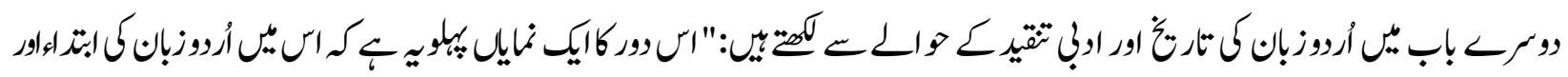

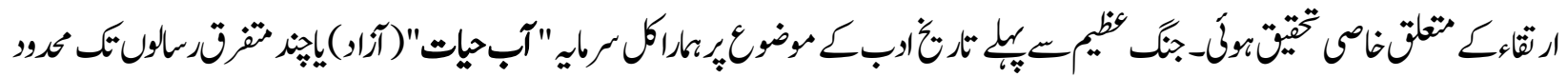

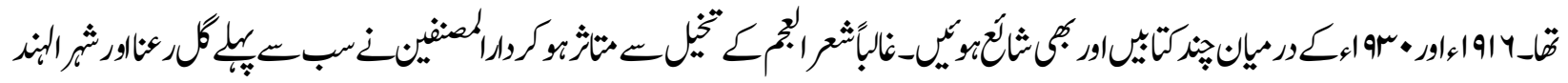

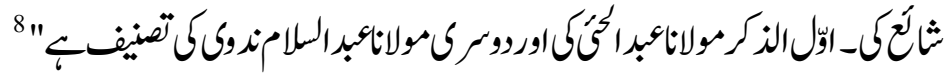

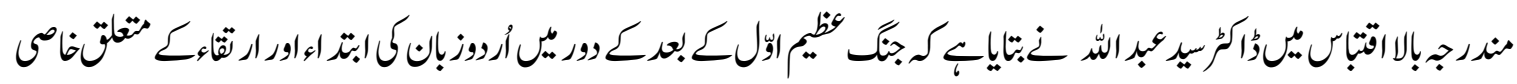

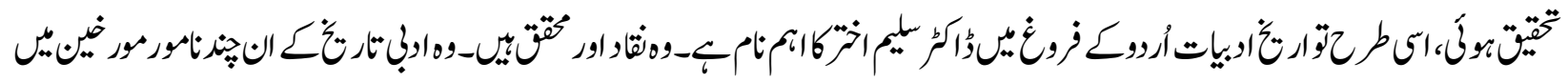

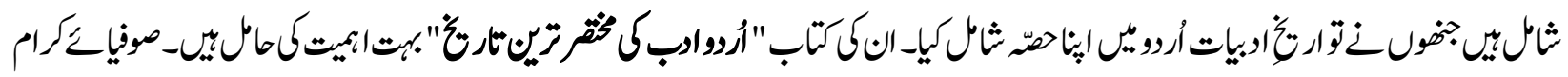

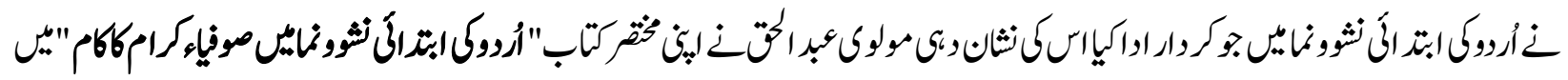

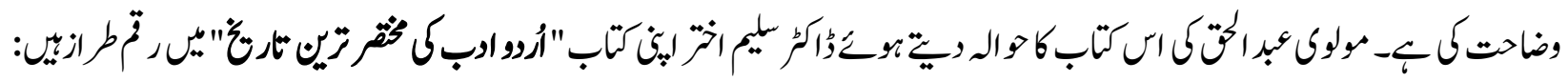

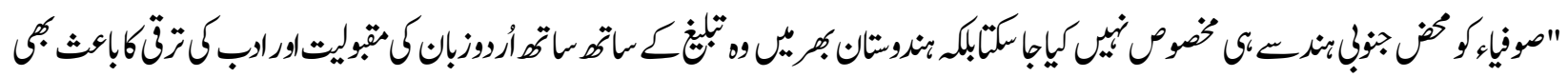

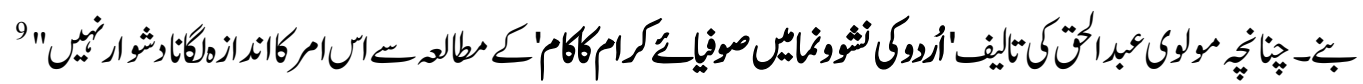

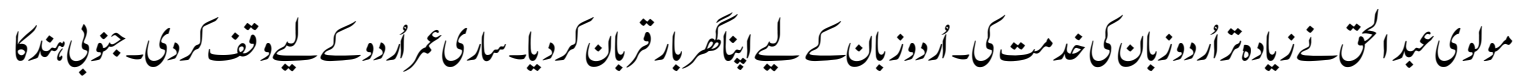

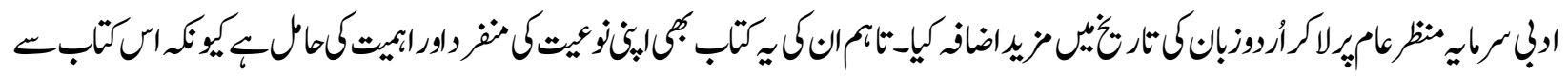

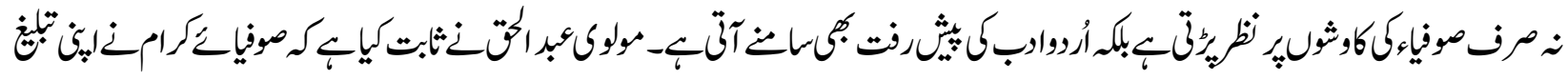

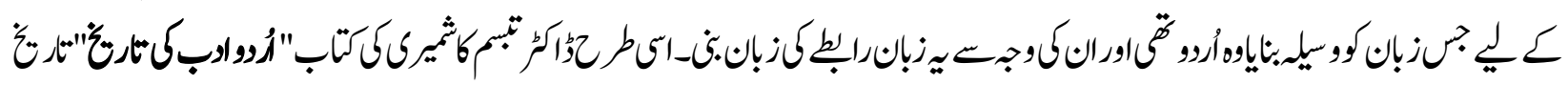

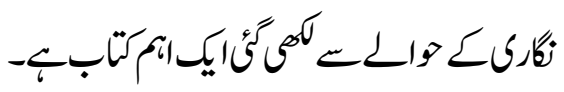

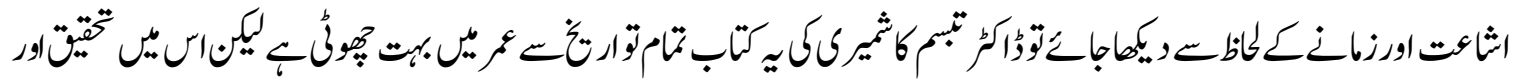

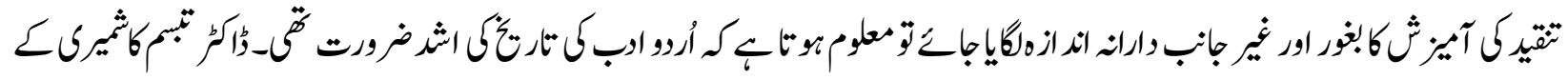

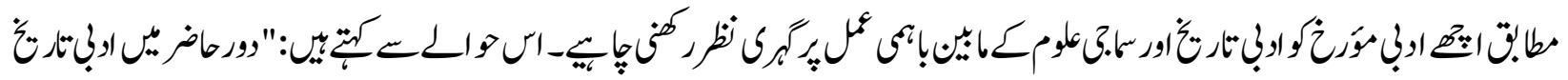

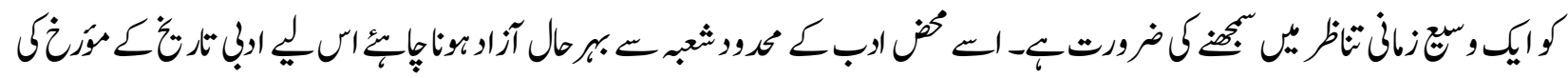

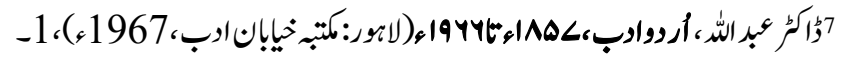

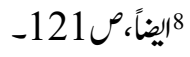

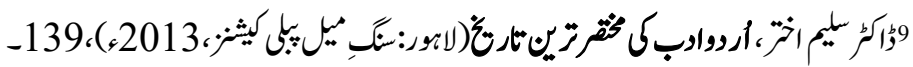




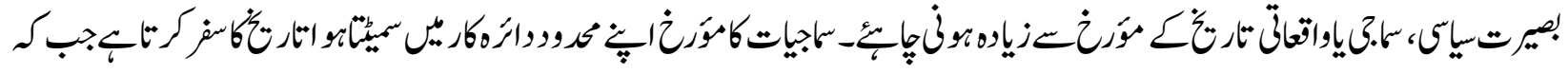

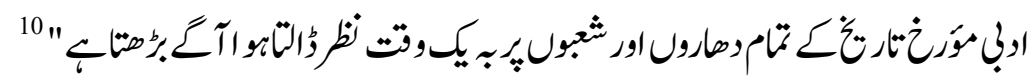

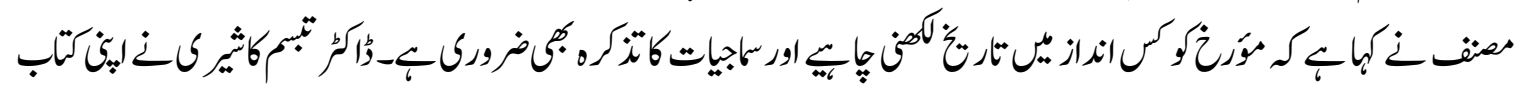

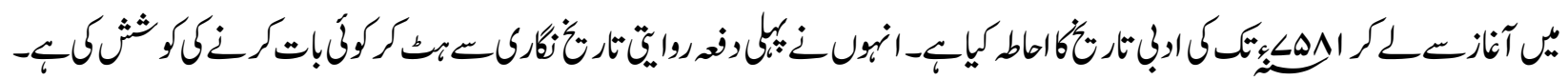

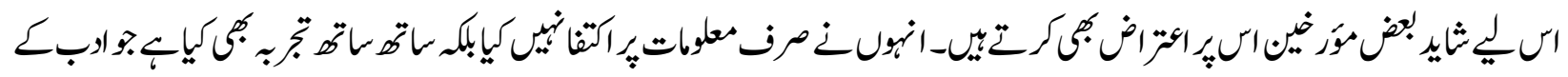

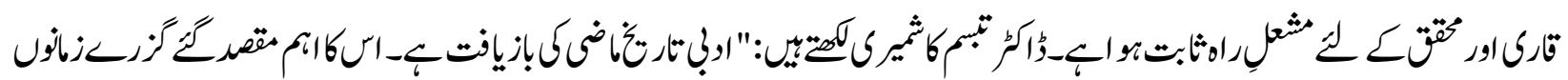

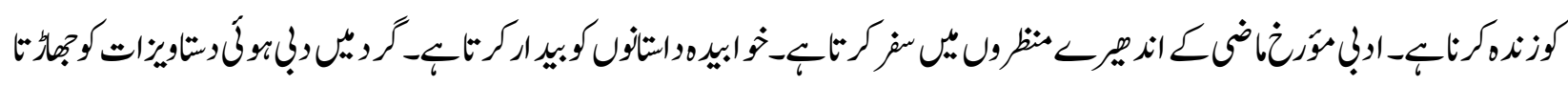

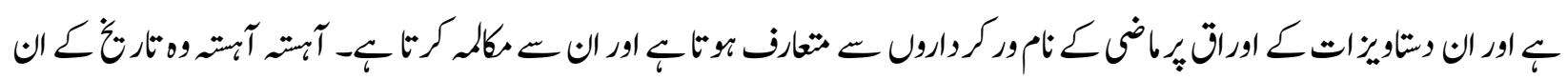

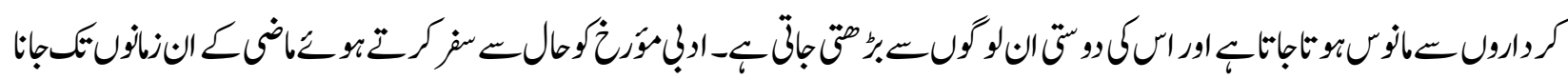

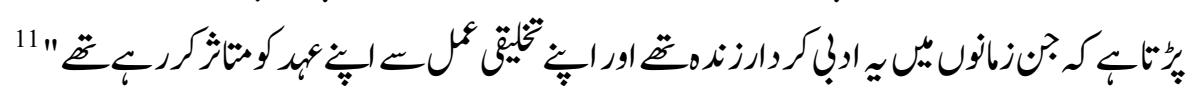

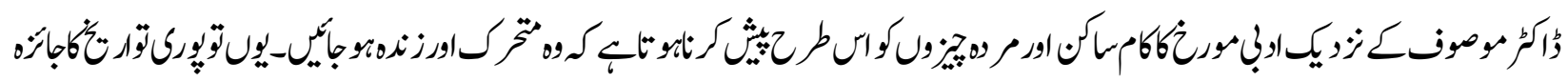

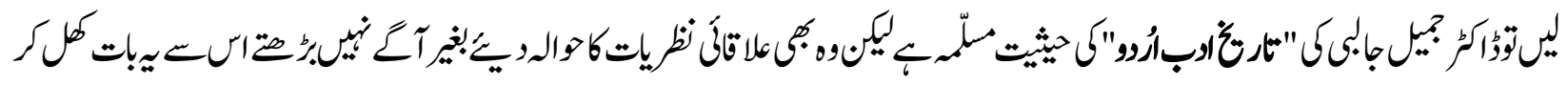

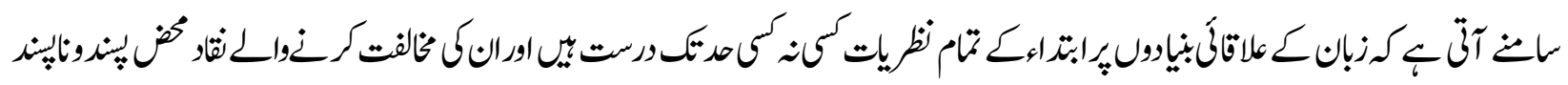

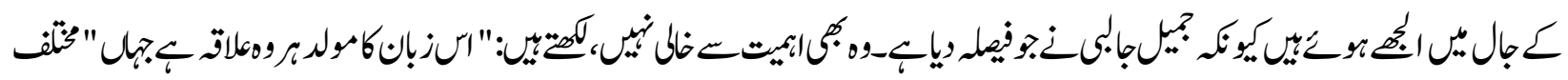

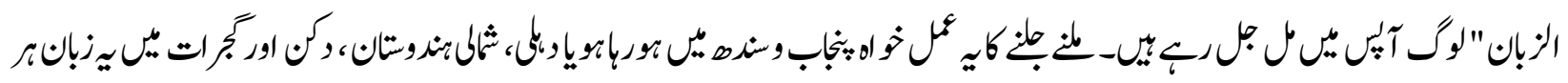

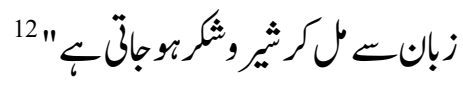

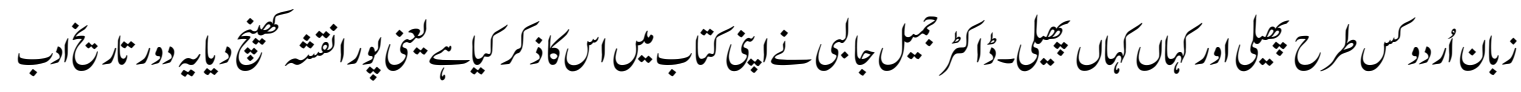

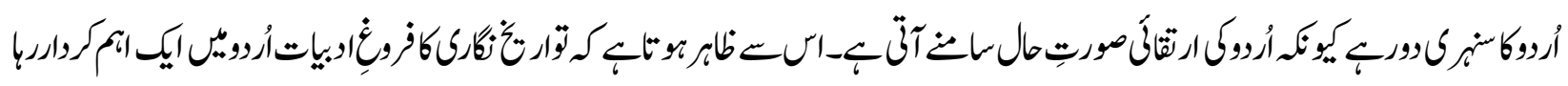

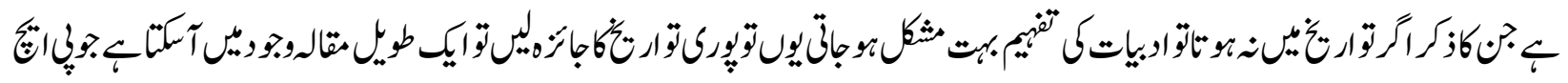

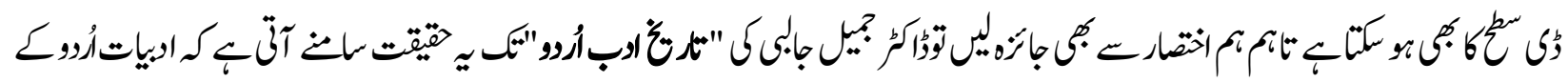

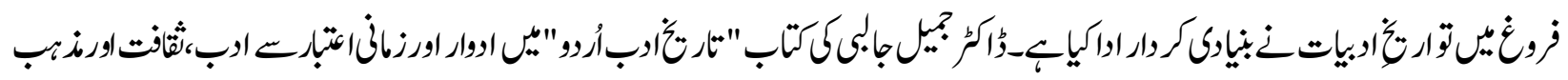

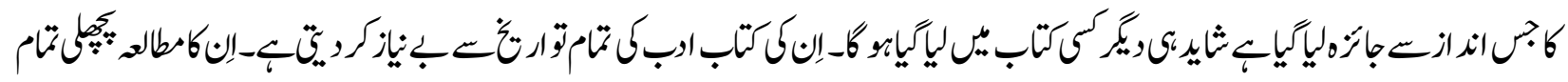

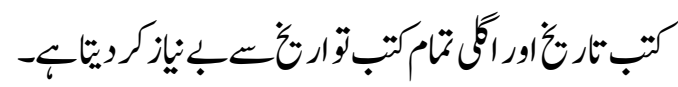
论领方

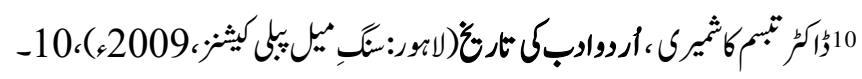

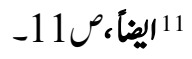

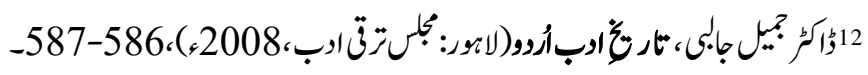

